\title{
Catu Daya Menggunakan Diode Tabung Hampa Tipe 5AR4 dan 6CA4
}

\author{
Gading Cassandra', Matias H. W Budhiantho' ${ }^{2}$, F. Dalu Setiaji ${ }^{3}$ \\ Program Studi Teknik Elektro, \\ Fakultas Teknik Elektronika dan Komputer \\ Universitas Kristen Satya Wacana, Salatiga \\ 1gadingc88@gmail.com, 2matias@staff.uksw.edu, 3ffdsetiaji@gmail.com
}

\begin{abstract}
Ringkasan
Catu daya untuk penguat tabung hampa terdiri atas dua bagian yaitu catu daya aras tinggi dan aras rendah. Dioda tabung hampa jenis 6CA4 dan 5AR4 digunakan sebagai penyearah catu daya aras tinggi. Catu daya yang dirancang mampu menghasilkan 280V/41mA, 443V/194mA, tegangan negatif -15V, 2 keluaran 6,3V/3A dan satu keluaran 6,3V/0,9A. Catu daya yang dirancang memiliki sistem soft-start dengan waktu bangkit 5 detik untuk catu daya aras tinggi dan 3 detik aras rendah. Efisiensi dari catu daya aras tinggi $54,2 \%$. Catu daya aras tinggi tegangan $280 \mathrm{~V}$ memiliki regulasi beban $28,8 \%$ dengan riak keluaran $0,052 \%$ dan catu daya $430 \mathrm{~V}$ memiliki regulasi beban $19,2 \%$ dengan riak keluaran $0,002 \%$. Pengujian penguat audio tabung 12AU7 dan EL34 dengan menggunakan catu daya yang dirancang menghasilkan tanggapan frekuensi rata $100 \mathrm{~Hz} \sim 4 \mathrm{kHz}$ dan THD 4,8 5,1\% yang cukup stabil dengan waktu pengujian dua jam terus menerus.
\end{abstract}

Kata kunci: Catu daya, tabung hampa, dioda, slow start

\section{Pendahuluan}

Meskipun teknologi tabung dianggap sudah kuno, penguat audio berbasis tabung hampa masih digemari hingga saat ini. Penguat tabung hampa memerlukan catu daya yang tepat. Dioda tabung hampa memiliki sifat slow-start yaitu dioda tabung hampa menghasilkan tegangan keluaran yang nilainya meningkat secara bertahap seiring dengan waktu pemanasan. Sifat slow-start sangat penting untuk menghindari pemberian tegangan tinggi secara mendadak pada penguat tabung hampa yang berpotensi merusakannya[1].

Perancangan catu daya tabung hampa sangat tergantung oleh tiga faktor utama yaitu beban catu daya, serta tegangan dan arus yang yang dihasilkan. Catu daya untuk penguat audio tabung dirancang setelah perancangan penguat audio dilakukan, agar dapat menyesuaikan dengan besarnya tegangan dan arus yang dibutuhkan penguat tersebut [2]. Dalam makalah ini perancangan catu daya tabung hampa dikhususkan untuk memenuhi kebutuhan penguat audio tabung hampa yang telah ada [3].

Penguat audio tersebut terbagi atas tiga bagian yaitu penguat awal, pembelah fasa dan penguat akhir. Bagian penguat awal dan pembelah fasa dirancang menggunakan tabung penguat triode 12AU7. Penguat akhir dirancang menggunakan tabung pentoda EL34. Diagram fungsional penguat tabung dengan catu dayanya ditunjukkan oleh Gambar 1 berikut ini. 


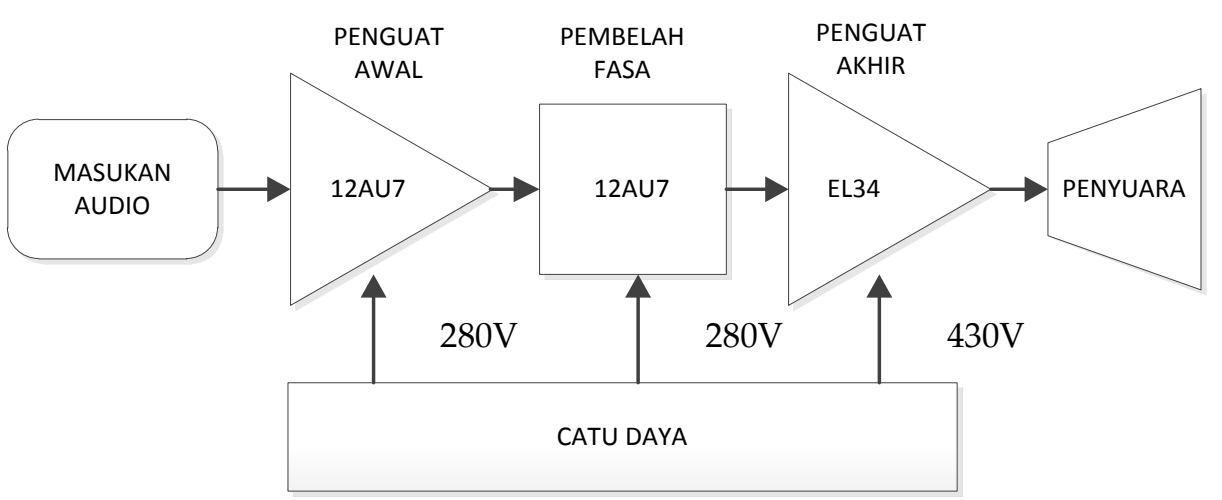

Gambar 1. Diagram kotak penguat audio tabung 12AU7 dan EL34[3]

Penguat audio menggunakan tabung 12AU7 dan EL34 memerlukan catu daya bertegangan tinggi yang terpisah untuk penguat awal, pembelah fasa dan penguat akhir. Bagian penguat awal dan pembelah fasa memerlukan catu $280 \mathrm{~V} / 50 \mathrm{~mA}$. Bagian penguat akhir memerlukan catu $430 \mathrm{~V} / 200 \mathrm{~mA}$. Selain catu daya bertegangan tinggi, penguat audio tabung 12AU7 dan EL34 memerlukan catu daya tegangan rendah untuk mencatu pemanas tabung penguat yaitu $6,3 \mathrm{~V} / 300 \mathrm{~mA}$ untuk pemanas tabung $12 \mathrm{AU} 7$ dan $6,3 \mathrm{~V}$ /1,5A untuk pemanas tabung EL34, kemudian diperlukan tegangan negatif $-15 \mathrm{~V}$ untuk mencatu regulator arus pada bagian pembelah fasa.

Penguat audio dengan tabung 12AU7 dan EL34 tersebut pada mulanya menggunakan catu daya berbasis penyearah dioda semi-penghantar[3]. Namun tanpa adanya perancangan sistem soft-start, lonjakan tegangan keluaran dari nol menuju tegangan tinggi puncak dalam waktu singkat dapat memperpendek usia tabung penguat. Oleh sebab itu pada makalah ini akan dirancang catu daya berbasis tabung hampa yang lebih tepat untuk memenuhi kebutuhan penguat tabung tersebut.

\section{Perancangan}

Fungsi utama catu daya adalah memenuhi kebutuhan daya seluruh bagian penguat audio. Catu daya untuk penguat audio tabung hampa terdiri atas dua bagian yaitu catu daya aras tinggi dan catu daya aras rendah. Catu daya aras tinggi berfungsi memenuhi kebutuhan tegangan dan arus piringan tabung hampa. Sedangkan catu daya aras rendah berfungsi memenuhi kebutuhan daya pemanas tabung penguat.

Catu daya aras tinggi dirancang dengan topologi catu daya linear menggunakan dioda tabung sebagai penyearah. Dioda tabung hampa digunakan untuk menghasilkan catu daya dengan sistem soft-start. Perancangan untai catu daya tabung hampa mengacu pada untai dasar catu daya tabung hampa yang ditunjukkan pada Gambar 2 berikut. 


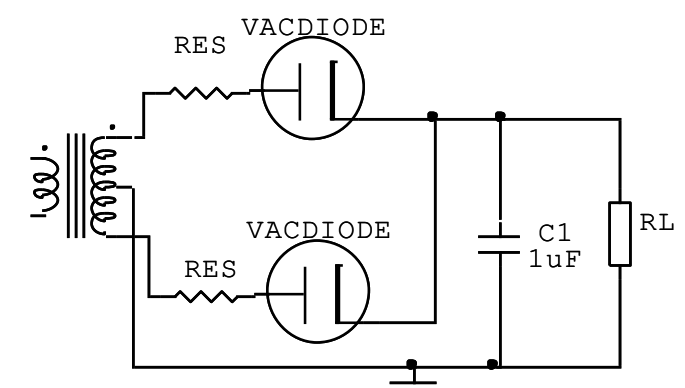

Gambar 2. Untai dasar catu daya dioda tabung hampa[4]

Tahap awal untuk mewujudkan catu daya tabung hampa adalah perancangan trafo penaik. Perancangan trafo penaik meliputi penentuan tegangan sekunder dari trafo penaik dan perhitungan nilai efektif hambatan lilitan sekunder trafo penaik $R_{E S}$.

Besarnya RES trafo penaik dihitung berdasarkan Persamaan (1) dan (2).

$$
\begin{gathered}
R_{E S}=R_{S}+N^{2} R_{P}+R_{A} \\
N=V_{S} / V_{P}
\end{gathered}
$$

Dimana $R_{P}$ adalah hambatan lilitan primer dan $R_{s}$ adalah hambatan lilitan sekunder dari trafo penaik, sedangkan $N$ adalah nisbah tegangan sekunder terhadap tegangan primer dari trafo penaik. Nilai $R_{A}$ merupakan hambatan tambahan yang diberikan di antara sambungan trafo dengan kaki anoda dari dioda tabung.

Langkah selanjutnya menentukan jenis dioda tabung hampa yang digunakan. Untuk memenuhi kebutuhan penguat yaitu $280 \mathrm{~V} / 50 \mathrm{~mA}$ dan $430 \mathrm{~V} / 200 \mathrm{~mA}$ digunakan dua dioda tabung hampa yaitu 6CA4 yang mampu menghasilkan tegangan $290 \mathrm{~V}$ dengan arus maksimal $150 \mathrm{~mA}$ dan tabung 5AR4 yang mampu menghasilkan tegangan $480 \mathrm{~V}$ dengan arus $250 \mathrm{~mA}$.

Arus piringan dan hambatan piringan merupakan dua komponen penting dari dioda tabung. Arus piringan dioda tabung dibedakan menjadi dua yaitu arus puncak piringan $\left(\hat{I}_{p}\right)$ dan arus rata-rata piringan $\left(\bar{I}_{p}\right)$. Dalam perancangan catu daya dengan dioda tabung hampa duplex sebagai penyearah gelombang penuh, besarnya arus rata-rata tiap piringan adalah setengah dari arus beban catu daya $\left(I_{L}\right)$ :

$$
\bar{I}_{p}=\frac{I_{L}}{2}
$$

Besarnya hambatan piringan ditentukan oleh besarnya arus puncak piringan dioda tabung hampa. Karena hambatan piringan merupakan fungsi arus menyebabkan tegangan jatuh, sedangkan amplitudo puncak isyarat yang dihasilkan dioda tabung hampa tidak diketahui maka arus puncak tidak dapat dihitung. Oleh karena itu digunakan asumsi awal untuk mendapatkan besarnya arus puncak piringan yaitu empat kali arus rata-rata piringan[4].

$$
\hat{I}_{p}=4 \times \bar{I}_{p}
$$

Hambatan piringan dioda tabung hampa didapat dengan membagi besarnya tegangan jatuh pada piringan saat pada arus puncak. Besarnya tegangan jatuh pada piringan berdasarkan besarnya arus puncak piringan didapat menggunakan grafik pada Gambar 3. 


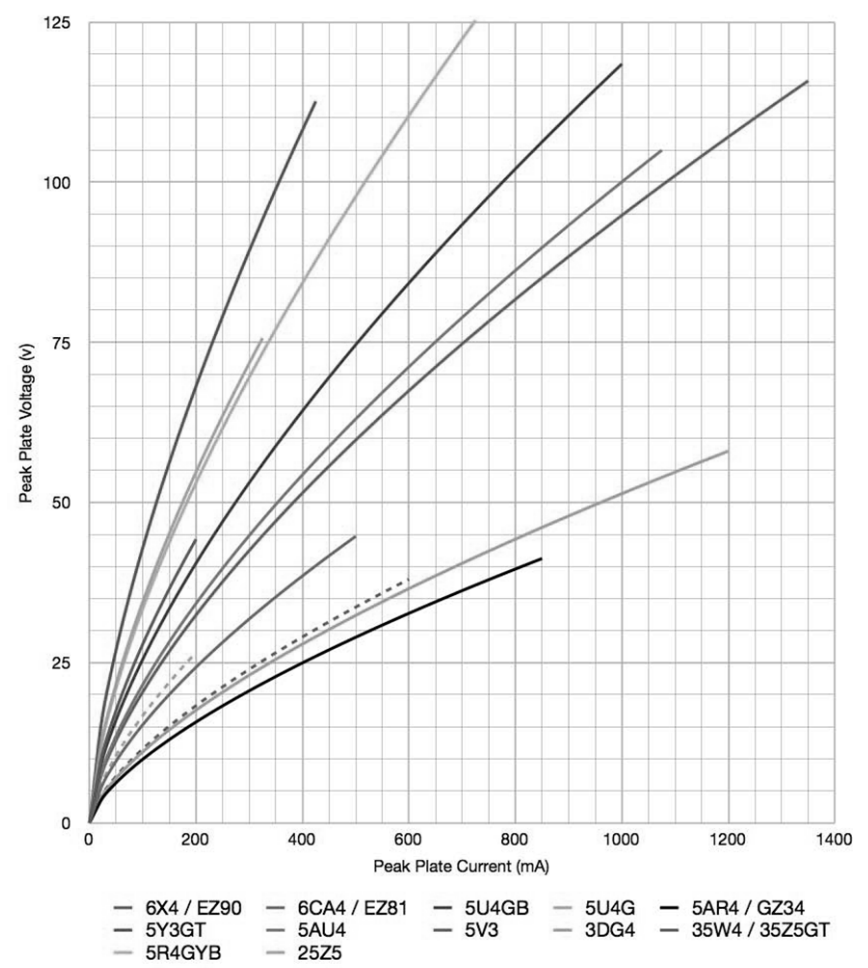

Gambar 3. Grafik tegangan jatuh piringan terhadap arus puncak piringan pada beberapa jenis dioda tabung hampa[5]

Besarnya hambatan piringan pada arus puncak dihitung menggunakan Persamaan:

$$
\hat{R}_{d}=\frac{\widehat{V}_{d}}{\hat{I}_{d}}
$$

Besarnya hambatan piringan pada arus rata-rata adalah sebesar 1,14 dari hambatan puncak piringan:

$$
\bar{R}_{d}=1,14 \times \hat{R}_{d}
$$

Karena adanya hambatan piringan pada arus rata-rata maka untai setara dari untai catu daya dengan tabung hampa ditunjukkan Gambar 4 berikut ini.

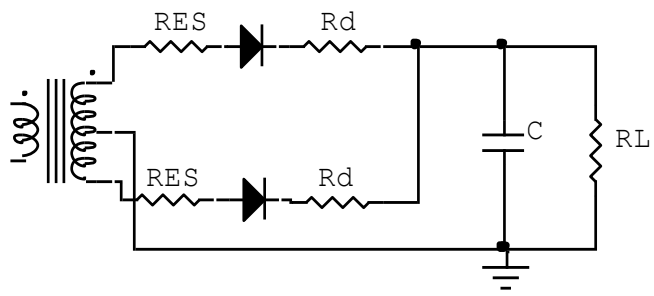

Gambar 4. Untai setara catu daya dengan dioda tabung hampa

Hambatan seri catu daya adalah penjumlahan antara hambatan piringan dioda tabung hampa dengan hambatan efektif lilitan sekunder trafo penaik. Hambatan seri catu daya terdiri atas hambatan seri pada arus puncak dan hambatan seri pada arus ratarata. Hambatan seri catu daya dapat dihitung dengan persamaan berikut:

$$
\begin{aligned}
& \hat{R}_{S}=R_{E S}+\hat{R}_{d} \\
& \bar{R}_{S}=R_{E S}+\bar{R}_{d}
\end{aligned}
$$


Dengan adanya hambatan seri catu daya maka untai catu daya pada gambar dapat disederhanakan lagi, ditunjukkan oleh Gambar 5 berikut ini.

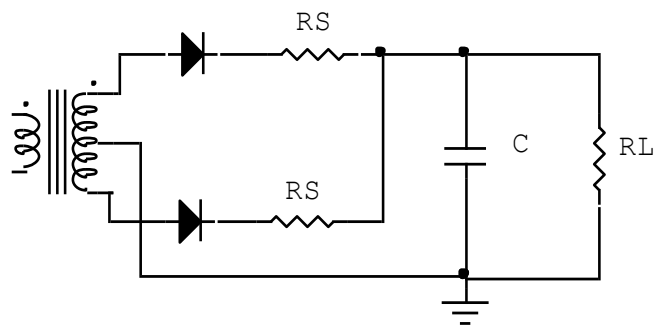

Gambar 5. Hambatan seri pada catu daya dioda tabung hampa

Untuk mendapatkan besarnya arus puncak piringan yang lebih tepat digunakan grafik arus puncak piringan dioda tabung hampa yang dibuat oleh Schade [4], seperti ditunjukkan Gambar 6.

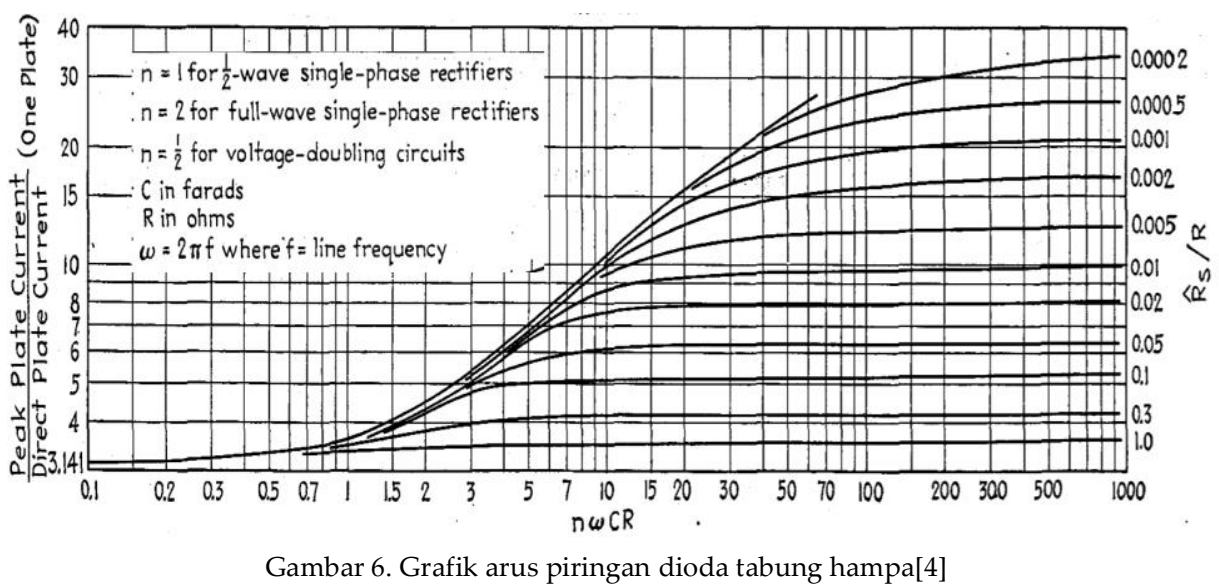

Grafik pada Gambar 6 menunjukkan besarnya nisbah arus puncak piringan dengan arus rata-rata piringan dipengaruhi oleh hambatan seri catu daya pada arus puncak $\hat{R}_{S}$, beban catu daya $R_{L}$, jumlah fasa $n$, frekuensi jala-jala dalam radian $\omega$, dan kapasitansi kapasitor tapis masukan $C$. Beban catu daya adalah nisbah dari tegangan dan arus keluaran catu daya, dihitung dengan persamaan berikut:

$$
R_{L}=\frac{V_{L}}{I_{L}}
$$

Arus puncak piringan yang didapat berdasarkan grafik Gambar 6 digunakan untuk menghitung ulang Persamaan (3) sampai (7) untuk mendapatkan besarnya hambatan piringan dioda tabung hampa dan hambatan seri catu daya yang lebih tepat.

Efisiensi penyearah adalah nisbah antara tegangan puncak dari keluaran trafo penaik tegangan $\left(E_{m}\right)$ dengan tegangan DC keluaran dari penyearah $\left(E_{d c}\right)$. Berikut adalah grafik efisiensi dari dioda tabung hampa sebagai penyearah gelombang penuh. 


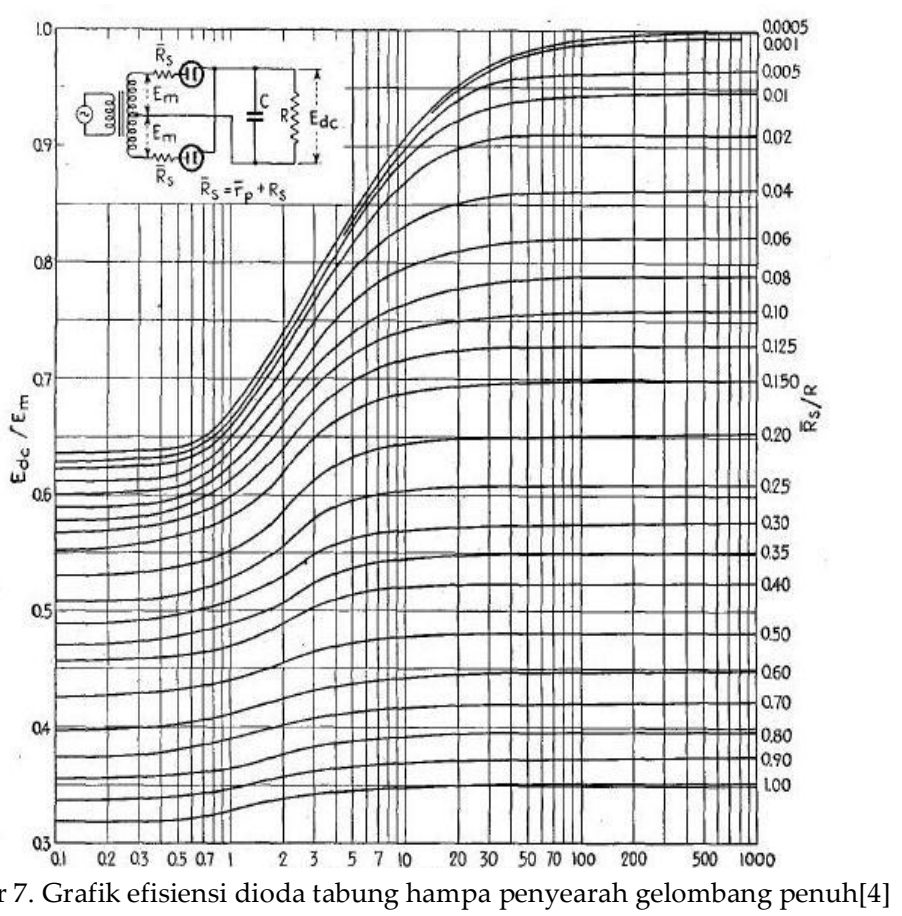

Berdasarkan grafik pada Gambar 7, efisiensi penyearah pada sumbu tegak sebelah kiri ditentukan oleh nisbah antara hambatan seri rata-rata catu daya $\bar{R}_{S}$ dan beban catu daya pada sumbu tegak sebelah kanan dan nilai, $\omega R C$, pada sumbu mendatar.

\subsection{Perancangan Catu Daya 280 V}

Pada perancangan catu daya $280 \mathrm{~V}$ digunakan trafo penaik $700 \mathrm{~V}$ RMS memiliki $R_{p}=$ $3,4 \Omega, R_{S}=116 \Omega$ sehingga nilai $R_{E S}$ berdasarkan Persamaan (1) adalah 124,7 . Berdasarkan lembar data dioda tabung hampa 6CA4 besarnya kapasitor maksimal yang digunakan sebagai tapis masukan adalah $60 \mu \mathrm{F}$, maka pada perancangan ini dipilih $50 \mu \mathrm{F}$. Dengan tegangan keluaran $V_{L}=280 \mathrm{~V}$ dan arus keluaran $I_{L}=50 \mathrm{~mA}$, beban setara dari catu daya $280 \mathrm{~V}$ berdasarkan Persamaan (8) besarnya adalah $5600 \Omega$. Sehingga besarnya nilai $\omega C R_{L}$ adalah 87,9 .

Arus beban catu daya $280 \mathrm{~V}$ adalah $I_{L}=50 \mathrm{~mA}$, sehingga arus rata-rata piringan berdasarkan Persamaan (10) adalah $25 \mathrm{~mA}$ dan arus puncak piringan berdasarkan Persamaan (11) diasumsikan 100mA. Berdasarkan lengkungan tabung hampa 6CA4 pada Gambar 3 dan Persamaan (4) didapat hambatan piringan pada arus puncak $\hat{R}_{d}$ adalah $150 \Omega$. Hambatan piringan pada arus rata-rata $\bar{R}_{d}$ berdasarkan Persamaan (5) adalah $171 \Omega$.

Hambatan seri pada arus puncak dan arus rata-rata dari catu daya didapat berdasarkan Persamaan (6) dan (7) adalah $\hat{R}_{S}=274,7 \Omega$ dan $\bar{R}_{S}=295,7 \Omega$. Digunakan resistor anoda $R_{A}$ sebesar $1 \mathrm{k} \Omega$ untuk memperkecil efisiensi penyearah dan mendapatkan tegangan keluaran yang diinginkan. Didapat nilai $\hat{R}_{S} / R_{L}=0,22$ dan $\bar{R}_{S} / R_{L}=0,23$. Dari grafik arus puncak piringan pada Gambar 6 didapat arus puncak piringan sebesar 4,6 kali dari arus piringan rata-rata. Dengan nilai arus puncak ini digunakan untuk melakukan perhitungan ulang hambatan piringan pada arus puncak dan pada arus rata-rata dan didapat $\hat{R}_{d}=147,8 \Omega$ dan $\bar{R}_{d}=168,5 \Omega$. Hasil akhir nisbah hambatan seri catu daya dengan beban catu daya adalah $\hat{R}_{S} / R_{L}=0,227$ dan $\bar{R}_{S} / R_{L}=0,23$. 
Berdasarkan grafik efisiensi penyearah pada Gambar 7 dengan nilai $\bar{R}_{S} / R_{L} \quad 0,23$, didapat efisiensi penyearah sebesar 0,63 sehingga tegangan keluaran penyearah:

$$
\begin{gathered}
\frac{E_{d c}}{E_{m}}=0,63 \\
E_{d c}=0,63 \times E_{m}=0,63 \times 1,414 \times 350=311,8 \mathrm{~V}
\end{gathered}
$$

\subsection{Perancangan Catu Daya $430 \mathrm{~V}$}

Pada perancangan catu daya $280 \mathrm{~V}$ digunakan trafo penaik 900V RMS memiliki $R P$

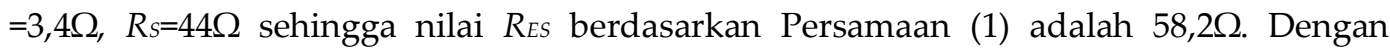
kapasitor masukan sebesar $50 \mu \mathrm{F}$. Tegangan keluaran $V_{L}$ adalah $430 \mathrm{~V}$ dan arus keluaran $I_{L}$ adalah 200mA sehingga beban setara dari catu daya 430V berdasarkan Persamaan (8) besarnya adalah $2150 \Omega$. Besarnya nilai $\omega C R_{L}$ adalah 33,76 .

Arus beban catu daya $430 \mathrm{~V}$ adalah $200 \mathrm{~mA}$ sehingga arus rata-rata piringan berdasarkan Persamaan (10) adalah $100 \mathrm{~mA}$ dan arus puncak piringan berdasarkan Persamaan (11) diasumsikan 400mA. Berdasarkan lengkungan tabung hampa 5AR4 pada Gambar 3 dan Persamaan (4) didapat hambatan piringan pada arus puncak $\hat{R}_{d}$ adalah $62,5 \Omega$. Hambatan piringan pada arus rata-rata $\bar{R}_{d}$ berdasarkan Persamaan (5) adalah $71,25 \Omega$.

Hambatan seri pada arus puncak dan arus rata-rata dari catu daya didapat berdasarkan Persamaan (6) dan (7) adalah $\hat{R}_{S}=120,7 \Omega$ dan $\bar{R}_{S}=129,5 \Omega$. Digunakan resistor anoda $R_{A}$ sebesar $100 \Omega$ untuk memperkecil efisiensi penyearah dan mendapatkan tegangan keluaran yang diinginkan. Didapat nilai $\hat{R}_{S} / R_{L}=0,103$ dan $\bar{R}_{S} / R_{L}=0,106$. Dari grafik arus puncak piringan pada Gambar 6 didapat arus puncak piringan sebesar 5 kali dari arus piringan rata-rata. Dengan nilai arus puncak ini digunakan untuk melakukan perhitungan ulang hambatan piringan pada arus puncak dan pada arus rata-rata dan didapat $\hat{R}_{d}=56 \Omega$ dan $\bar{R}_{d}=63,84 \Omega$. Hasil akhir nisbah hambatan seri catu daya dengan beban catu daya adalah $\hat{R}_{S} / R_{L}=0,1$ dan $\bar{R}_{S} / R_{L}=0,103$.

Berdasarkan grafik efisiensi penyearah pada Gambar 7 dengan nilai $\bar{R}_{S} / R_{L}$ 0,103, didapat efisiensi penyearah sebesar 0,76 sehingga tegangan keluaran penyearah:

$$
\begin{gathered}
\frac{E_{d c}}{E_{m}}=0,76 \\
E_{d c}=0,63 \times E_{m}=0,76 \times 1,414 \times 450=483,6 \mathrm{~V}
\end{gathered}
$$

\subsection{Perancangan Regulator Tegangan Tinggi}

Regulator LM317 di sini berfungsi menstabilkan tegangan keluaran penyearah menjadi nilai tegangan yang diharapkan dari keluaran catu daya. Berdasarkan lembar data tegangan masukan IC LM317 dibatasi minimal 2,5V dan maksimal 37V di atas tegangan keluaran. Untuk menjaga agar tegangan masukan-keluaran berada dalam batas kemampuan LM317 digunakan dioda zener 1N7044 30V.

Berdasarkan Gambar 8 keluaran regulator ditentukan oleh $R_{1}$ dan $R_{2}$. Penulis menggunakan dioda zener, transistor NPN dan resistor $R_{E}$ untuk membatasi masukan LM317. Beda tegangan antara masukan dan keluaran LM317 dapat dihitung berdasarkan Persamaan berikut.

$$
V_{i n_{L M 317}}-V_{o_{L M 317}}=V_{\text {zener }}-V_{b e}-V_{R_{E}}
$$




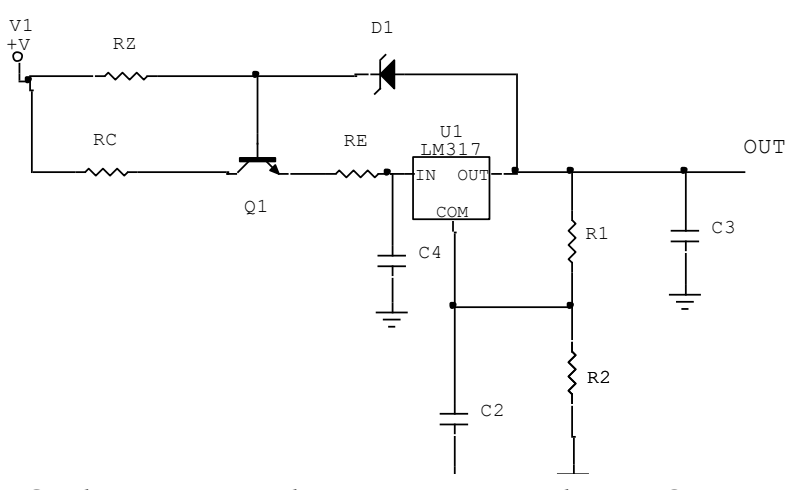

Gambar 8. Untai regulator tegangan tinggi dengan IC LM317

Berdasarkan Persamaan beda tegangan dibatasi oleh tegangan dioda zener yang digunakan. Resistor $R_{1}$ berfungsi untuk menurunkan tegangan $V_{C E}$ transistor NPN dan resistor $R z$ menentukan besarnya arus dioda zener. Arus kerja minimal dioda zener adalah $5 \mathrm{~mA}$ sehingga besarnya $R z$ dihitung berdasarkan Persamaan berikut.

$$
R_{z}=\frac{\left(V_{\text {in }}-V_{o}\right)_{\text {regulator }}-V_{\text {zener }}}{5 \times 10^{-3}}
$$

Selain membatasi tegangan masukan LM317, resistor emitor $R_{E}$ juga berfungsi membatas arus keluaran regulator. Besarnya arus keluaran maksimal regulator dihitung berdasarkan Persamaan berikut.

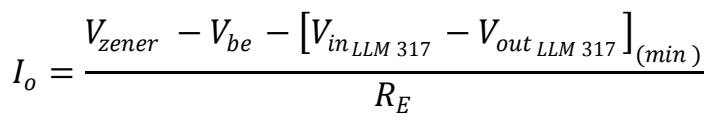

Berikut adalah untai catu daya $280 \mathrm{~V}$ dan $430 \mathrm{~V}$ secara keseluruhan:

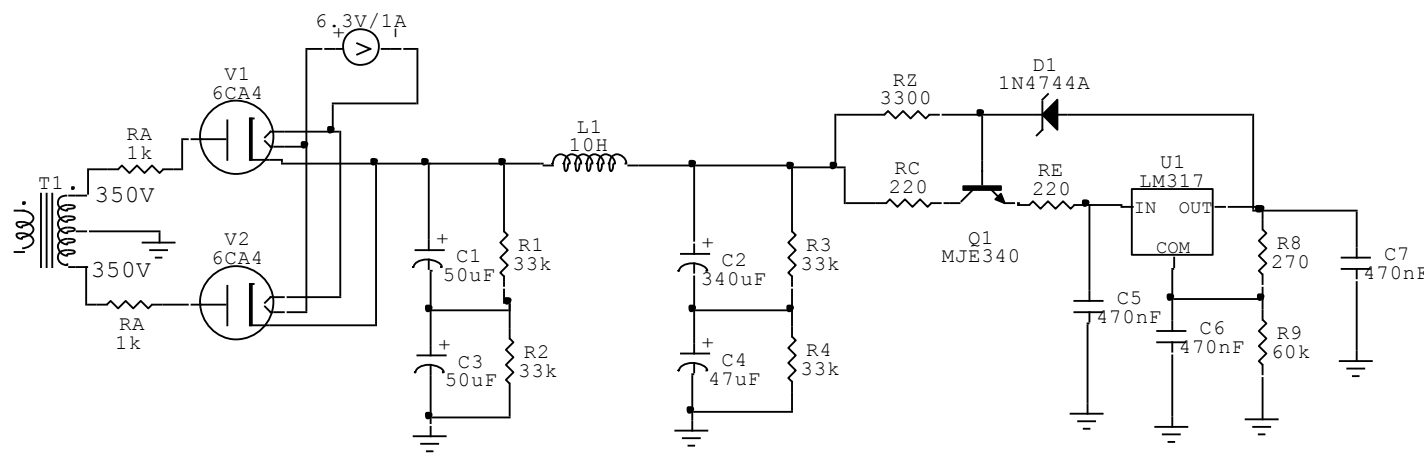

Gambar 9. Untai catu daya 280V

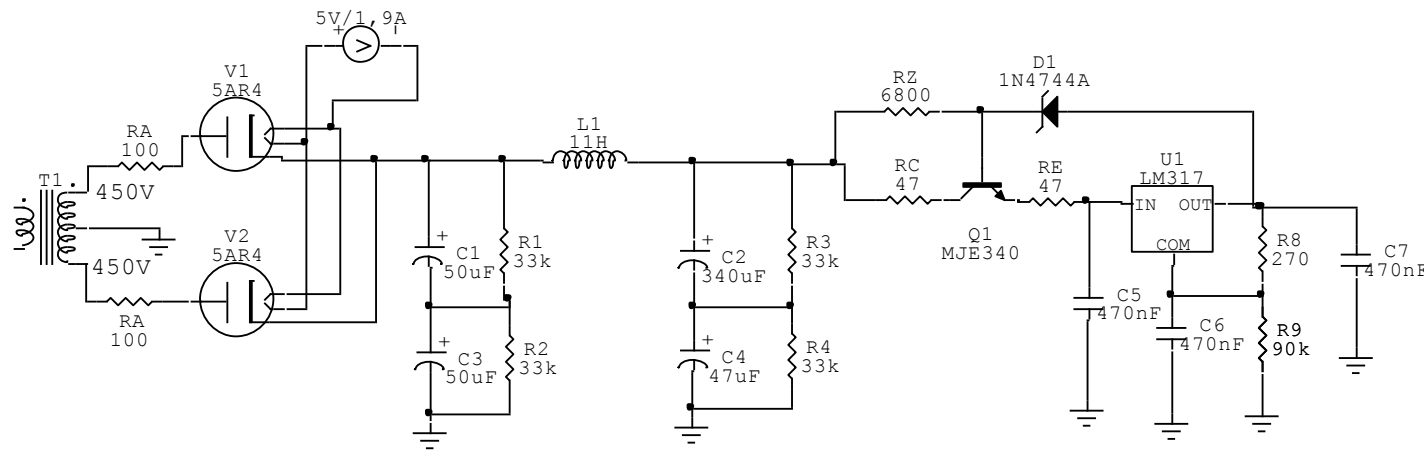

Gambar 10. Untai catu daya 430V 


\subsection{Perancangan Catu Daya Pemanas}

Catu daya pemanas dirancang menghasilkan tegangan DC. Komponen yang akan digunakan adalah IC regulator LM317. Sistem soft-start dirancang dengan menambahkan komponen transistor PNP, Rss dan Css seperti yang ditunjukkan pada Gambar 11.

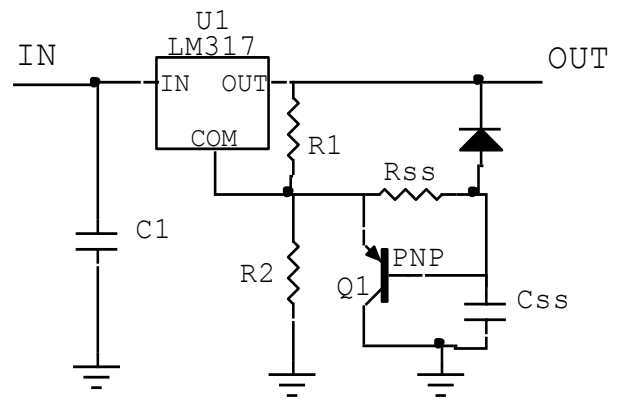

Gambar 11. Untai LM317 dengan sistem soft-start

Pada keadaan awal, sebelum dimuati kapasitor CSS akan bersifat hubung singkat yang menyebabkan kaki adjust (COM) LM317 terhubung dengan tanah (ground) karena adanya transistor PNP. Kondisi demikian menyebabkan keluaran LM317 sama dengan tegangan referensi LM317 yaitu 1,25V. Kemudian kapasitor Css akan dimuati oleh arus yang melewati Rss sehingga tegangan kapasitor $C_{S S}$ naikdan menyebabkan tegangan keluaran LM317 ikut naik. Lamanya waktu naik dipengaruhi oleh konstanta waktu yang menentukan lamanya pengisian kapasitor.

$$
V_{C}=V_{R_{2}}\left(1-e^{-t / \tau}\right)
$$

Dimana $V_{C}$ adalah tegangan kapasitor, $V_{R 2}$ adalah tegangan $R_{2}, t$ adalah lamanya waktu naik catu daya dan $\tau$ adalah konstanta waktu. Konstanta waktu didapat berdasarkan perkalian Rss dan Css.

$$
\tau=R_{s s} \times C_{s s}
$$

\section{Hasil Pengujian dan Analisis}

Pengujian catu daya dilakukan berdasarkan acuan Power Supply Testing[6] yang diterbitkan oleh Agilent Technologies Incorporated. Untuk pengujian penguat audio tabung 12AU7 dan EL34 mengacu pada Guidelines for Measuring Audio Power Amplifier[7] yang diterbitkan oleh Texas Instrument Incorporated.

Pengujian pertama dilakukan pada catu daya aras tinggi untuk mengetahui tegangan dan arus keluaran serta waktu naik dari catu daya aras tinggi pada keadaan penguat tanpa isyarat masukan. Hasil pengujian ditunjukkan pada Gambar 12 dan 13.

Berdasarkan Gambar 12 dan 13, catu daya aras tinggi mampu menghasilkan tegangan $280 \mathrm{~V}$ dengan arus $41 \mathrm{~mA}$ dengan waktu naik tegangan 6 detik dan tegangan $443 \mathrm{~V}$ dengan arus $194 \mathrm{~mA}$ dengan waktu naik tegangan 5 detik.

Selanjutnya dilakukan pengujian regulasi catu daya aras tinggi untuk mengetahui tegangan catu daya aras tinggi pada keadaan tanpa beban, dengan beban penguat audio tabung tanpa diberi isyarat masukan dan dengan beban penguat audio tabung saat menghasilkan daya maksimal. Hasil pengujiannya ditunjukkan oleh grafik pada Gambar 14 dan 15 berikut. 


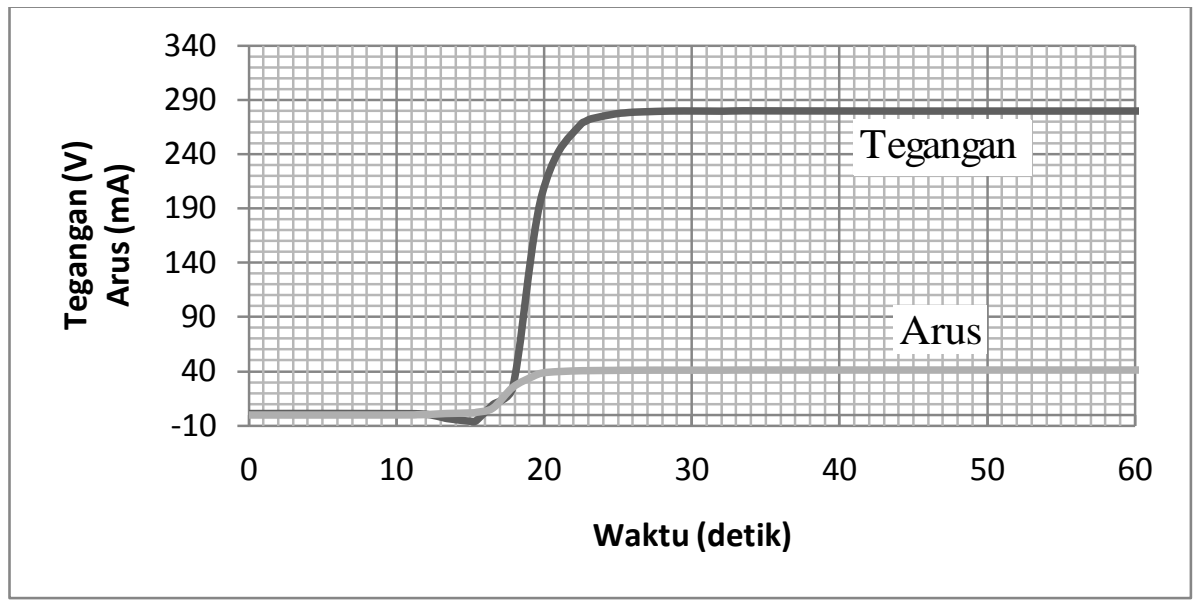

Gambar 12. Grafik tegangan dan arus keluaran catu daya 280V

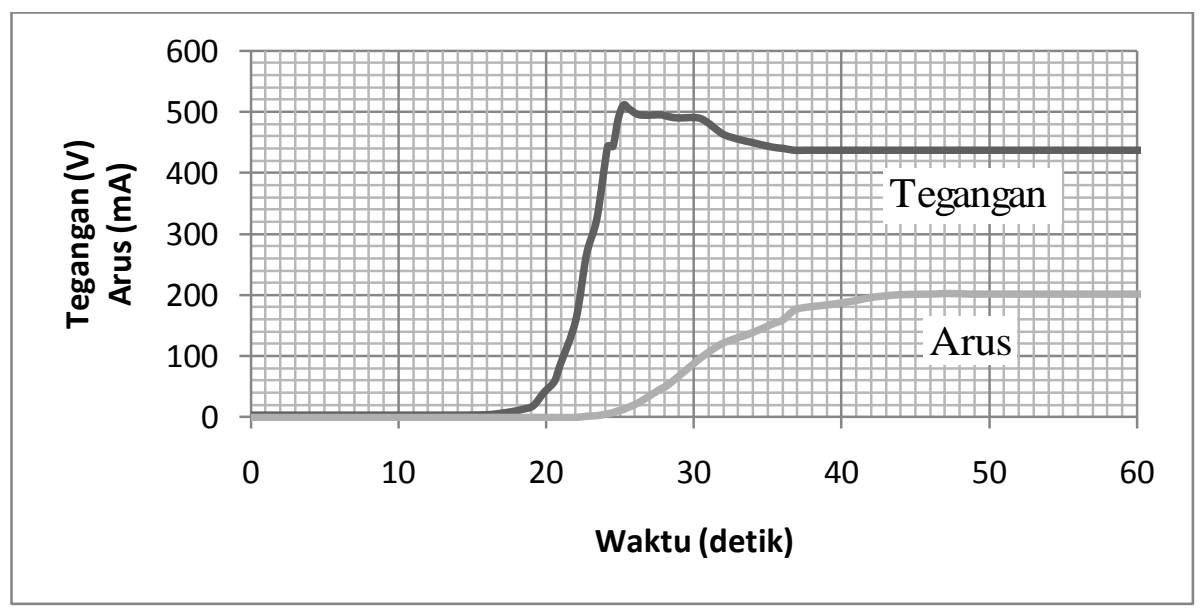

Gambar 13. Grafik tegangan dan arus keluaran catu daya 430V

Dengan hasil yang didapat berdasarkan Gambar 14 dan 15, besarnya tegangan jatuh catu daya aras tinggi saat penguat menghasilkan daya maksimal terhadap tegangan catu daya saat penguat tanpa isyarat masukan, untuk catu daya $280 \mathrm{~V}$ adalah $0,071 \%$ dan catu daya $430 \mathrm{~V}$ adalah $3,45 \%$.

Selanjutnya untuk mengetahui efisiensi catu daya aras tinggi dilakukan pengukuran tegangan dan arus masukan catu daya dimana didapat tegangan masukan adalah dan arus masukan adalah sehingga daya masukan catu daya aras tinggi :184,3 Watt rms. Daya keluaran catu daya $280 \mathrm{~V}$ adalah $11,5 \mathrm{Watt}$ dan catu daya $430 \mathrm{~V}$ adalah 88,5 Watt sehingga efisiensi catu daya aras tinggi adalah $54,2 \%$. Efisiensi daya yang didapat tidak memenuhi spesifikasi yaitu $>70 \%$. Hal ini dikarenakan tegangan jatuh dioda tabung yang besar dan penggunakan resistor anoda $R_{A}$ sehingga menambah hambatan seri dan tegangan jatuh catu daya. 


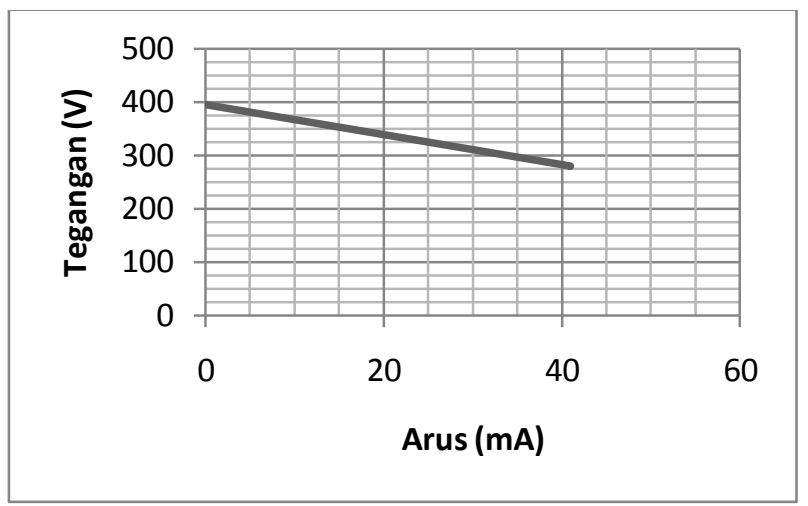

Gambar 14. Grafik regulasi beban catu daya 280V

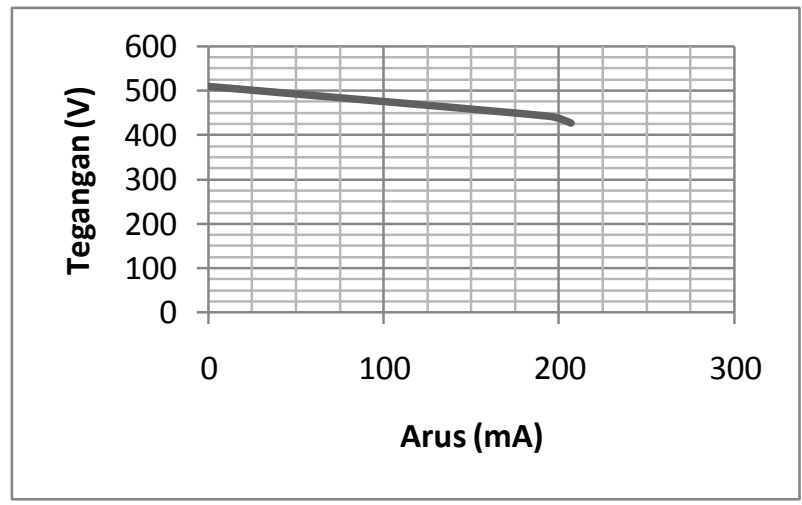

Gambar 15 Grafik regulasi beban catu daya $430 \mathrm{~V}$

Untuk pengujian catu daya aras rendah dilakukan dengan mengukur tegangan dan waktu naik dari tegangan keluaran dari catu daya pemanas tabung 12AU7 dan catu daya pemanas tabung EL34 sebagai catu daya aras rendah. Hasilnya ditunjukkan pada Gambar 16.

Berdasarkan Gambar 16, waktu naik tegangan catu daya pemanas saat tanpa beban adalah 3 detik. Setelah catu daya dihubungkan dengan pemanas tabung hampa waktu naik tegangan catu daya pemanas adalah 6,7 detik untuk pemanas tabung 12AU7 dan 16 detik untuk pemanas tabung EL34. Perbedaan lamanya waktu naik dari catu daya pemanas tabung hampa 12AU7 dan EL34 kemungkinan karena perbedaan kebutuhan daya dimana pemanas tabung hampa $12 \mathrm{AU} 7$ membutuhkan catu daya 6,3V/0,3A sementara pemanas tabung hampa EL34 membutuhkan catu daya 6,3V/1,5A. Arus puncak pemanas tabung hampa $12 \mathrm{AU} 7$ adalah $2.5 \mathrm{~A}$ dengan catu daya tanpa sistem softstart dan 1,9A dengan catu daya sistem soft-start. Arus puncak pemanas tabung hampa EL34 adalah 6,13A dengan catu daya tanpa sistem soft-start dan 4A dengan catu daya sistem soft-start.

Pengujian terakhir dilakukan pada penguat audio tabung 12AU7 dan EL34 yang diaktifkan menggunakan catu daya yang sudah direalisasikan tersebut. Dalam pengujian ini diukur kemantapan tanggapan frekuensi dan THD (total harmonic distortion) dari penguat yang bekerja selama dua jam. Pengujian dilakukan dengan membangkitkan isyarat derau putih dan isyarat sinus $1 \mathrm{kHz}$ dengan menggunakan perangkat lunak SpectraLab untuk mengetahui tanggapan frekuensi dan THD penguat. Hasilnya ditunjukkan pada Gambar 17 dan 18. 


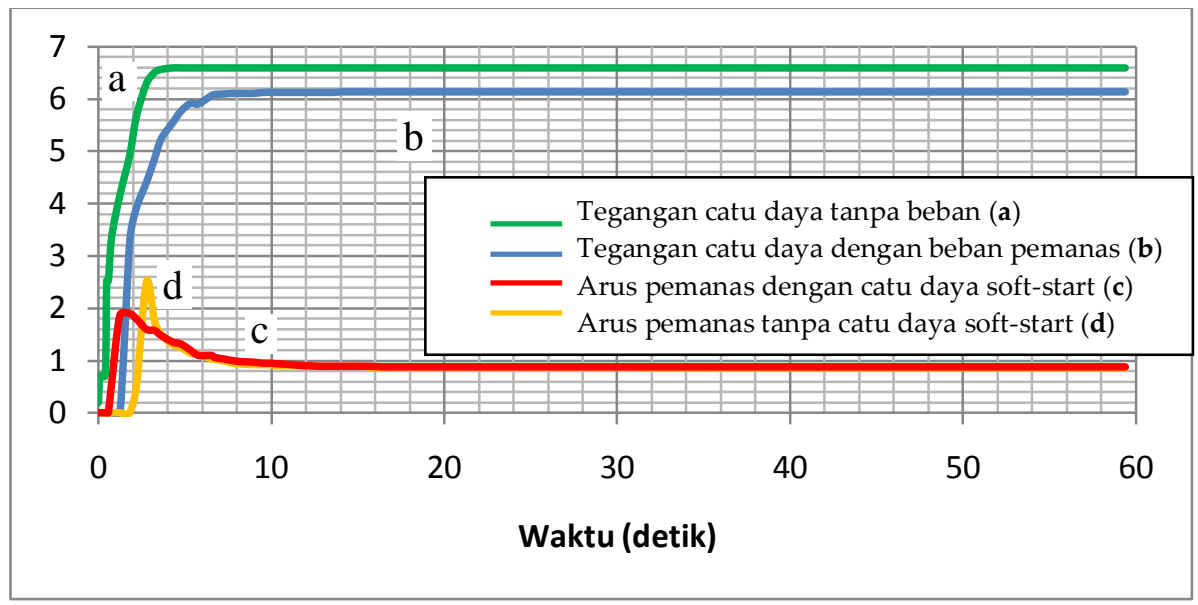

(a)

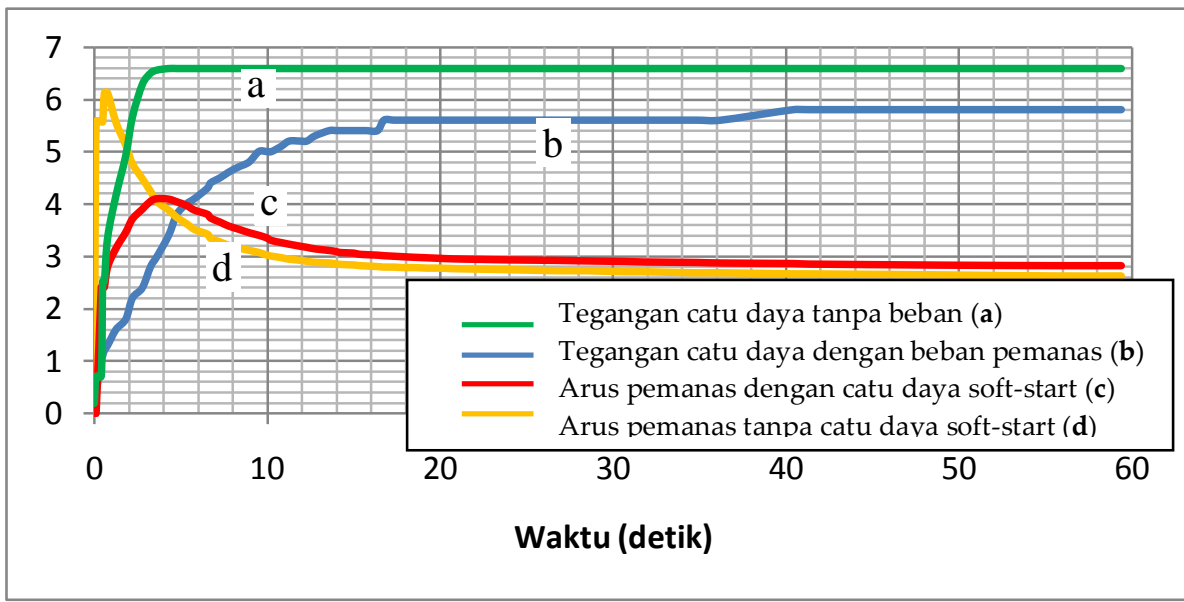

(b)

Gambar 16. Grafik tegangan dan arus catu daya pemanas (a) tabung 12AU7 (b) tabung EL34

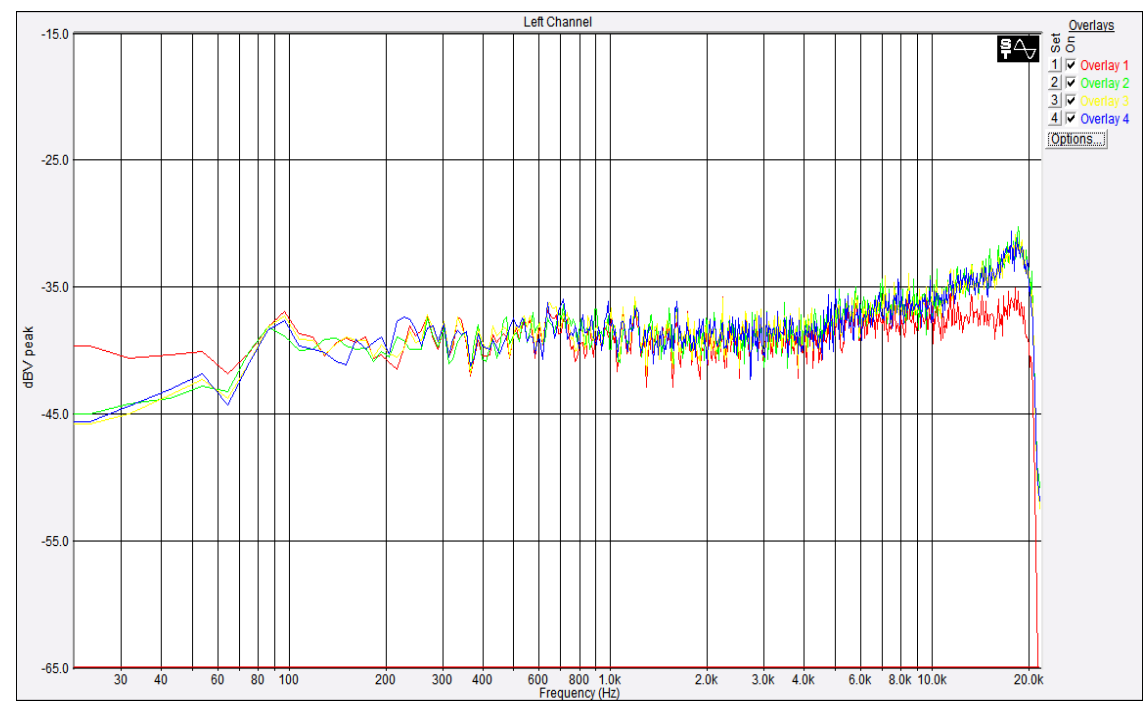

Gambar 17 Tanggapan frekuensi penguat audio tabung 12AU7 dan EL34 


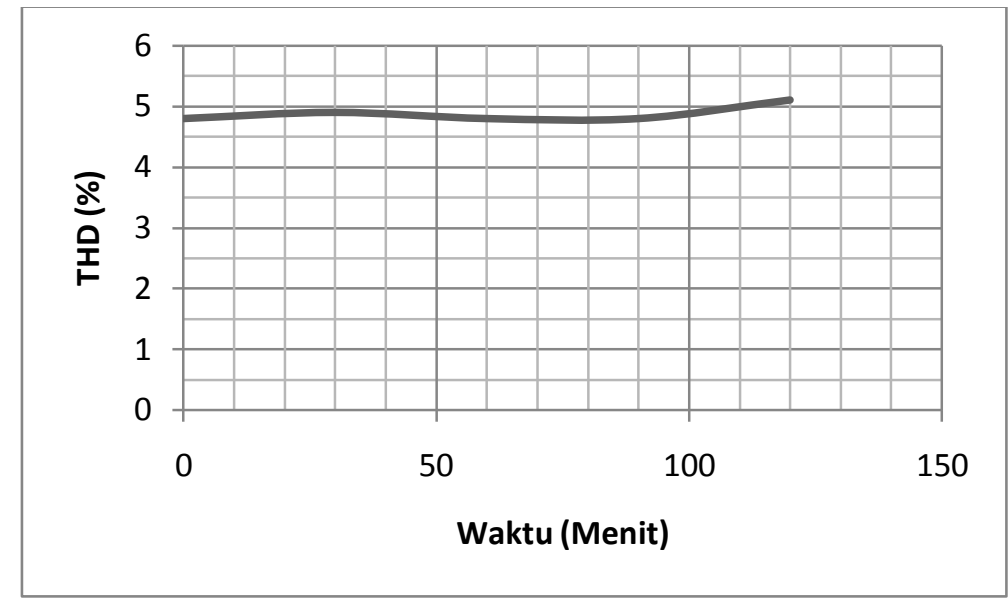

Gambar 18. Hasil pengukuran THD penguat dengan isyarat uji $1 \mathrm{kHz}$

\section{Kesimpulan}

Catu daya untuk penguat audio tabung 12AU7 dan EL34 yang telah dirancang terdiri atas dua bagian yaitu catu daya aras tinggi dan catu daya aras rendah. Catu daya aras tinggi berfungsi untuk menyediakan kebutuhan daya piringan tabung hampa, direalisasikan menggunakan dioda tabung hampa jensi 6CA4 dan 5AR4. Penggunaan dioda tabung hampa memberikan efek soft-start pada tegangan keluaran sehingga tepat untuk mencegah kerusakan tabung hampa akibat pemberian tegangan tinggi mendadak. Catu daya aras rendah berfungsi untuk memenuhi kebutuhan pemanas tabung hampa, dirancang dengan sistem soft-start dan menghasilkan tegangan DC. Catu daya aras rendah terbukti dapat menurunkan arus puncak yang ditarik oleh pemanas seperti yang ditunjukkan pada pengujian catu daya aras rendah.

Berdasarkan hasil pengujian, berikut adalah spesifikasi akhir dari catu daya yang telah dibuat :

1. Mampu menyediakan tegangan DC $443 \mathrm{~V} / 194 \mathrm{~mA}$ dan $280 \mathrm{~V} / 41 \mathrm{~mA}$ sebagai keluaran catu daya aras tinggi saat penguat tanpa isyarat masukan.

2. Tegangan jatuh $0,071 \%$ untuk catu daya $280 \mathrm{~V}$ dan $3,45 \%$ untuk catu daya $430 \mathrm{~V}$ saat volume maksimal penguat.

3. Efisiensi catu daya aras tinggi $54,2 \%$.

4. Mampu menyediakan tegangan DC $2 \times 6,3 \mathrm{~V} / 3 \mathrm{~A}, 6,3 \mathrm{~V} / 900 \mathrm{~mA}$ sebagai keluaran aras rendah.

5. Waktu naik (rise time) catu daya 280V 6 detik, 430V 5 detik dan catu daya tingkat rendah 3 detik.

6. Regulasi beban catu daya aras tinggi sebesar $28,8 \%$ untuk catu daya $280 \mathrm{~V}$ dan $19,2 \%$ untuk catu daya $430 \mathrm{~V}$.

7. Riak keluaran catu daya aras tinggi $7,07 \mathrm{mV}$ rms untuk catu daya $280 \mathrm{~V}$ dan 70.7 $\mathrm{mV}$ rms untuk catu daya $430 \mathrm{~V}$ pada keadaan beban catu daya maksimal.

8. Pengujian penguat audio tabung 12AU7 dan EL34 sebagai target perancangan catu daya menghasilkan tanggapan frekuensi rata $100 \mathrm{~Hz} \sim 4 \mathrm{kHz}$ dengan isyarat uji derau putih dan THD yang mantap dengan nilai $4,8 \sim 5,1 \%$ pada pengujian selama 2 jam. 


\section{Daftar Pustaka}

[1] L. Olsion, The Amity, Raven, and Aurora, [Online], http://www.nutshellhifi.com/triodel.html, diakses tanggal 13 Oktober 2013.

[2] M. Jones, Valve Amplifier", 3 $3^{\text {rd }}$ Ed, Newness, 2003

[3] Y.A. Yudiarwan, M.H.W. Budhiantho, F.D. Setiaji, Perancangan Penguat Awal dan Akhir Menggunakan Tabung 12AU7 (GL-5814) dan EL34, Salatiga: Skripsi FTEK-UKSW, 2008

[4] H.J. Reich, Theory and Applications of Elektron Tubes, $2^{\text {nd }}$ Ed, New York, McGraw-Hill, 1944.

[5] M. Renaud, Power Supply Design for Vacuum Tube Amplifiers, [Online], http://diyaudioprojects.com/Technical/Tube-Power-Supplies/, diakses tanggal 13 Oktober 2013.

[6] Agilent Technologies, Inc., Agilent AN 372-1 Power Supply Testing, http://cp.literature.agilent.com/litweb/pdf/5952-4190.pdf, [Online], diakses tanggal 13 Oktober 2013.

[7] Texas Instruments, "Guidelines for Measuring Audio Power Amplifier Perfomance", http://www.ti.com.cn/cn/lit/an/sloa068/sloa068.pdf, diakses tanggal 13 Oktober 2013. 